\title{
Manifestações neurológicas e COVID19
}

\section{Neurological manifestations and COVID19}

\author{
Marco Antonio Araújo Leite ${ }^{1}$ (1) \\ Marco Orsini ${ }^{2}$ (1) \\ Jacqueline Stephanie Fernandes do Nascimento ${ }^{3}$ (1) \\ 'Universidade Federal Fluminense (Niterói). Rio de Janeiro, Brasil. maaraujoleite@yahoo.com \\ ${ }^{2}$ Universidade Federal Fluminense (Rio de Janeiro), Universidade Iguaçu (Iguacu), Universidade de Vassouras (Vassouras). Rio de Janeiro, Brasil. \\ orsinimarco@hotmail.com \\ universidade Iguaçu (Iguaçu). Rio de Janeiro, Brasil. jac.fn@hotmail.com
}

\begin{abstract}
"In a few weeks, our world has become a very different place. Those things that we took for granted have been severely disrupted, and, suddenly, we all fear for our own mortality and health of our loved ones." Stoess/ J, Bhatia KP, Merello $\mathrm{M}^{1}$
\end{abstract}

Em 30 de dezembro de 2019, o médico oftalmologista chinês Li Wenliang alertou um grupo de colegas médicos sobre a possibilidade de estarem diante de uma nova Síndrome Respiratória Aguda Grave (sigla inglesa SARS), provavelmente de causa infecciosa. Isso ocorreu na província de Wuhan, na República Popular da China, onde se suspeita ter surgido o caso índice da COVID19². Em fevereiro de 2020, contraindicando o emprego de termos xenofóbicos e preconceituosos, a OMS cunhou a sigla COVID 19, que significa COrona VIrus Disease, sendo 19 uma referência ao ano de 2019, data da descrição dos primeiros casos da doença ${ }^{3}$. Desde as primeiras descrições, muito tem sido escrito sobre o vírus SARS COV-2 (Severe acute respiratory syndrome coronavirus 2). Infelizmente, igualmente às primeiras autoridades sanitárias de Wuhan, que posteriormente se retrataram, possibilitando o controle da epidemia na China, alguns governantes mundiais diante da calamidade por nós vivenciada desdenham do impacto dessa nefasta doença, por inicialmente diminuírem gastos em saúde pública e mais recentemente persistirem com o incentivo à quebra do isolamento social ${ }^{4,5}$.

Em poucos meses, testemunhamos a transformação de uma afecção de localização regional, caracterizada inicialmente por um quadro febril e respiratório de ocorrência em idosos, em uma pandemia, de uma doença que acomete vários aparelhos e sistemas do corpo humano de pessoas das mais variadas faixas etárias. Desse modo, o sistema nervoso tanto o central como o periférico são afetados.

Teoriza-se, atualmente, sobre a possibilidade da contaminação do sistema nervoso por duas vias. Em uma delas haveria participação de nervo craniano e em outra a disseminação seria hematológica6. Um estudo, demonstrou, na infecção pelo SARS-COV 1, portanto, outro coronavírus, em rato transgênico para receptor humano de enzima de conversão da angiotensina 2, que o nervo olfatório tem papel fundamental nessa neuroinvasão7. Em humanos essa via também foi proposta para outros vírus que acometem o sistema respiratório. Desse modo, estudo de série de casos, análise do líquido cefalorraquiano, bem como de necrópsias, sugerem, por analogia com outros agentes biológicos, ser neurotrópico o SARS COV2 ${ }^{8,9}$. 
A prevalência das manifestações neurológicas parece ser de cerca de $36 \%$, sendo que o sistema nervoso central é o afetado em 2/3 dos casos. Dor de cabeça (cefaleia) tem sido referida em 13 a 15\% dos pacientes sintomáticos. Há várias possibilidades de sua causa, dentre as quais exacerbação de enxaqueca previamente manifesta, sintoma de meningite, encefalite, entre outras. Geralmente, nos casos mais leves é pouco intensa e pode durar poucos dias. Cerca de 15\% podem apresentar mialgia, por vezes, localizada e às vezes difusa, leve a intensa e que pode chegar, raríssimas vezes à rabdomiólise. A anorexia não é incomum. Perda do olfato ou anosmia e perda da gustação são sintomas/sinais cuja frequência é um tanto confusa. Podem ou não coexistirem com sinais gripais do tipo coriza. Constituem uma das primeiras manifestações da COVID19 e são de surgimento abrupto. O surgimento de um dos dois, mesmo na ausência de tosse ou febre, por vezes, até exclusivamente, no momento atual, deve ser considerado como muito sugestivo de COVID19. Síncope (desmaio) por conta da hipóxia também pode surgir nos estágios intermediários ou mais avançados da doença (após o sétimo ou décimo dia). Nos estados intermediários mais graves, em alguns casos, surge a encefalopatia (geralmente secundária a alterações metabólicas, hipóxia e fármacos). Crises epilépticas e outras alterações mentais como confusão mental (desorientação, dellirium) e estupor ocorrem em sua decorrência. Essas manifestações e alterações do comportamento, por vezes, indicam encefalite causada pela COVID 19. A inflamação do encéfalo ocorre entre as pessoas mais graves ou sob cuidados de terapia intensiva ${ }^{10,11}$.

Doenças cerebrovasculares tem sido inicialmente verificadas em pessoas vulneráveis em que ocorre sobreposição de eventos, de riscos tais como HAS grave, diabete melito e dislipidemia, combinados às descompensações no volume sanguíneo e outros distúrbios pelo estado crítico da infecção pela COVID19. Entretanto, cada vez mais têm sido publicados relatos de casos de pacientes mais jovens manifestando AVC. Há alguns dias, um artigo norte-americano descreveu o surgimento de AVC em quatro pessoas cujas idades variavam dos 31 aos 47 anos. Duas delas eram saudáveis e em uma o AVC foi a primeira manifestação da COVID1912. Dessa forma, um sem número de alterações da motricidade e do tônus, advém dessas situações. Em cerca de 1/3 dos casos, o sistema nervoso periférico vem sendo também acometido. Síndrome de Guillain Barrè, neuropatia do doente crítico e outras vêm sendo referidas ${ }^{13}$.
No contexto da reabilitação, a fisioterapia, desde os primeiros momentos esteve presente. $O$ manuseio da ventilação não invasiva e invasiva, bem como a prática da pronação, por ocasião da síndrome mais dramática da COVID19, a insuficiência respiratória, tem tido no fisioterapeuta uma atividade essencial. Mais recentemente, a reabilitação neurológica, pelo exposto anteriormente, vem ganhando importância ${ }^{14}$.

\section{Referências}

1. StoessI AJ, Bhatia KP, Merello M. Movement Disorders in the World of COVID-19. This article has been copublished in Movement Disorders and Movement Disorders Clinical Practice. Movement Disorders Clinical Practice. 2020;7(4):355-356. doi: 10.1002/mdc3.12952

2. Green A. Li Wenliang. Lancet. 2020;395(10225):682. doi: $10.1016 /$ S0140-6736(20)30382-2

3. Fundação Osvaldo Cruz. Covid-19 / Perguntas e respostas. [Internet]. 2020. Disponível em: https://portal.fiocruz.br/pergunta/ por-que-doenca-causada-pelo-novo-virus-recebeu-o-nome-decovid-19

4. Burki T. COVID-19 in Latin America. Lancet Infect Dis 2020. 2020;20(5):547-548. doi: 10.1016/S1473-3099(20)30303-0

5. Garrett L. COVID-19: the medium is the message. Lancet. 2020;395(10228):942-943. doi: 10.1016/S0140-6736(20)30600-0

6. Felice FG, Tovar-Moll F, Moll J, Munoz DP, Ferreira ST. Severe Acute Respiratory Syndrome Coronavirus 2 (SARSCoV-2) and the Central Nervous System. Trends Neurosci. 2020;pii:S0166-2236(20):30091-6. doi: 10.1016/j.tins.2020.04.004

7. Netland J, Meyerholz DK, Moore S, Cassell M, Perlman S. Severe acute respiratory syndrome coronavirus infection causes neuronal death in the absence of encephalitis in mice transgenic for human ACE2. J Virol. 2008;82(15):7264-75. doi: $10.1128 /$ IVI.00737-08

8. Zhou L, Zhang M, Wan J, Gao J. Sars-Cov-2: Underestimated damage to nervous system. Travel Med Infect Dis. 2020;24:101642. doi: 10.1016/j.tmaid.2020.101642

9. Xu Z, Shi L, Wang Y, Zhang J, Huang L, Zhang C et al. Pathological findings of COVID-19 associated with acute respiratory distress syndrome. Lancet Respir Med. 2020;8(4):420-422. doi: 10.1016/ $\underline{\text { S2213-2600(20)30076-X }}$

10. Mao L, Wang M, Chen S, He Q, Chang J, Hong C et al. Neurological Manifestations of Hospitalized Patients with COVID-19 in Wuhan, China: a Retrospective Case Series Study. MedRxiv. 2020. doi: 10.1101/2020.02.22.20026500 
11. Li Y, Wang M, Zhou Y, Chang J. Acute Cerebrovascular Disease Following COVID-19: A Single Center, Retrospective, Observational Study. SSRN Electronic Journal. 2020. doi: 10.2139/ssrn.3550025

12. Oxley TJ, Mocco J, Majidi S, Kellner CP, Shoirah $\mathrm{H}$, Singh IP et al. Large-Vessel Stroke as a Presenting Feature of Covid-19 in the Young. N Engl J Med. 2020; 382:e60. doi: 10.1056/NEJMc2009787

13. Padroni M, Mastrangelo V, Asioli GM, Pavolucci L, Abu-

Rumeileh S, Piscaglia MG et al. Guillain-Barré syndrome following COVID-19: new infection, old complication? J Neurol. 2020:1-3. doi: 10.1007/s00415-020-09849-6

14. Thomas P, Baldwin C, Bissett B, Boden I, Gosselink R, Granger $\mathrm{CL}$ et al. Physiotherapy management for COVID-19 in the acute hospital setting: clinical practice recommendations. J Physiother. 2020;66(2):73-82. doi: 10.1016/j.jphys.2020.03.011 